\title{
Beyond Punishment: Doping, Deterrence, and Moral Disengagement
}

\section{Miranda P Kaye ${ }^{1 *}$ and lan D Boardley ${ }^{2}$}

${ }^{1}$ Department of Exercise and Sport Sciences, Ithaca College, NY, USA

${ }^{2}$ University of Birmingham, USA

\begin{abstract}
When athletes use performance enhancing drugs, they violate the nature of sport. With the recent doping scandals in Olympic and professional sport, current deterrence methods do not appear to be effective. Thus it is important to better understand why athletes engage in Performance Enhancing Drug (PED) use. Evidence associating doping with moral disengagement is accumulating and suggests that mechanisms of moral disengagement may play an important role in facilitating doping by allowing athletes to rationalize their PED use. We suggest that a more detailed understanding of moral disengagement could assist in reducing PED use in the future.
\end{abstract}

Keywords: Performance enhancing drug use; Morality

Charges of doping in professional and Olympic sports have reached unprecedented heights. This August, seven-time Tour de France winning cyclist Lance Armstrong abandoned his defense against charges of systematic doping leveled against him by the United States Anti-Doping Agency. Doping offences also resulted in Major League Baseball suspending National League MVP Melky Cabrera and former Cy Young Award winner Bartolo Colon for fifty games, and the International Olympic Committee subsequently stripping shot putter Nadezhda Osapchuk of the gold medal she won during the recent London games. Although some observers consider sports doping to be common [1], its true extent is unknown. Depending on the methodology employed and the sport in question, prevalence estimates range from $1 \%$ to $90 \%$ of athletes [2].

Almost as wide ranging as the estimates of prevalence are the reasons for doping listed in the literature. Both psychological and sociological factors need to be taken into account. For instance, social and financial interests can drive athletes to dope $[3,4]$. There are also suggestions that many professional athletes see doping as necessary to be competitive [5]. Other researchers have suggested that performance outcomes, prestige, and achievement influence Performance Enhancing Drug (PED) use [6,7]. Finally, from a social perspective, group influences (e.g., in- or out-group influence) and influential others (e.g., sports doctors, competitors, coaches) can affect an athlete's decision to dope $[6,8]$.

\section{Deterrence}

Anti-doping policy largely relies upon a detection-based deterrence approach in which athletes who are caught doping are punished in order to deter other athletes from doping [9]. In other words, the potential consequences of being caught (e.g., being banned from competition) are intended to deter athletes from doping [6]. However, it seems that more and more athletes are taking a "defensive doping" approach, whereby athletes believe they must dope to be competitive at the elite level, due to the perception that PED use is required to make it to the podium [10]. Such perceptions have the potential to induce contenders in a specific competition to resort to doping. For example, as noted recently in the Melbourne's Herald Sun, Cadel Evans, who finished eighth in the 2005 Tour de France, could be seen as the "moral winner" of the Tour, for the seven cyclists who beat him were all subsequently either investigated, sanctioned, or banned for drug-related offenses [11]. The desire to win at all costs appears to drive some athletes to utilize advances in science to provide them with new and unethical ways to become citius, altius, forties ("faster, higher, stronger").

The contest between doping and detection is an arms race between new detection methods and increasingly sophisticated methods to avoid detection [12]. Because the regulators may be at a disadvantage $[13,14]$, it has been suggested that this issue can be combated through voluntary testing. The Voluntary Anti-Doping Association (VADA), for instance, promotes anti-doping in boxing and mixed martial arts by separating the sports into two parallel leagues, one with doping restrictions and one without $[15,16]$. Neither parallel leagues nor voluntary testing, however, are likely to solve the problem. Even if the voluntary testing and education promoted by VADA become available for more sports, it is likely that it would not be fully effective. Indeed, as King argues, parallel leagues could actually intensify the problem [17]. First, there is the same issue of athletes breaking the rules and using PEDs in the clean league, where incentives to cheat would persist. Drug-testing procedures would still be required, necessitating the same mechanisms of testing, adjudication, and punishment that currently exist. That having such parallel leagues does not prevent doping in non-doping divisions is evidenced in the non-doping power lifting and bodybuilding federations, which are rife with athletes who contravene the rules even though legal doping divisions are available [18].

Second, allowing doping does not create a level playing field. Athletes with the largest financial resources can employ the most expensive sports doctors and use the most sophisticated techniques. In fact, it has been said that the cost is in the region of $\$ 50,000$ per annum [19]. To stay competitive, athletes without the financial resources may resort to self-medication on the basis of advice or information gathered from others. Not only would such an approach be dangerous from a health perspective, it is also unlikely to be far less effective than being part of a doping program being coordinated by a specialist sports doctor with considerable knowledge of the latest products and practices available.

Another relevant issue is that spectators would no longer be able to relate to the performances of professional athletes. Scenarios in which bionic and robotic baseball players hit a home run every time have been imagined [20]. With these scenarios, it would be difficult to judge the performances of technologically- and biologically-enhanced athletes.

*Corresponding author: Miranda $\mathrm{P}$ Kaye, Department of Exercise and Sport Sciences, Ithaca College, Ithaca, NY 14850, USA, E-mail: mkaye@ithaca.edu

Received October 15, 2012; Accepted October 27, 2012; Published October 29 2012

Citation: Kaye MP, Boardley ID (2012) Beyond Punishment: Doping, Deterrence, and Moral Disengagement. J Sports Med Doping Stud 2:e127. doi:10.4172/2161$0673.1000 \mathrm{e} 127$

Copyright: @ 2012 Kaye MP, et al. This is an open-access article distributed under the terms of the Creative Commons Attribution License, which permits unrestricted use, distribution, and reproduction in any medium, provided the original author and source are credited. 
Thus, the enhanced league would become an ascetic exhibition and far removed from what we currently consider sport to be [21].

Finally, the health implications of doping remain an issue. Although one can argue that the principle of autonomy gives athletes a right to use their body as they wish [17], some athletes may be prepared to risk their health whereas others may not. Because experimental testing of the long-term effects of PED in healthy human beings is potentially dangerous and therefore unethical, little is known about severity of the health risks associated with doping. In addition, observational data is difficult to obtain and analyze when athletes consume multiple products simultaneously, and often at supraphysiological dosages. Thus, developing a league which allows athletes to use PEDs is problematic from a number of perspectives.

\section{Morality}

Regardless of league divisions and testing, the underlying issue is that obtaining an artificial advantage through doping is prima facie immoral. Sports doping involves the use of substances (such as anabolic steroids or human growth hormone) or medical techniques (such as blood doping or gene manipulation) for the primary purpose of gaining an unfair - and illegal - advantage [22]. When one considers the harm it causes (physical and psychological), and the injustice and violations of rights inflicted [23], doping is clearly a moral violation. In a sporting context, participants' rights center on fair competition and an equal opportunity to strive for success [24]. The use of PEDs violates the World Anti Doping Agency's rules, violates competitors' rights and is a form of cheating [25]. Actions, such as doping, that lead to injustice, short- and long-term harm to health, or the violation of participants' rights are considered to be immoral [26]. In fact, it has been argued that no other sport violations, be it violence, game fixing, or cheating, violate the ethos of sport as much as doping does [27]. Thus, understanding the psychological characteristics of athletes who dope may be just as important as deterrent approaches based on testing, catching, and penalizing athletes who dope.

From an ethical perspective, one can take the philosophical point of view and focus on the theoretical background of moral development, or emphasize the demands of the sport itself as a highly competitive domain in which finishing in second place is sometimes seen as unacceptable. From a theoretical perspective, sport ethics have been studied from an achievement-goal perspective [28,29], a sociallearning or structural developmental approach [30,31], and a socialpsychological approach [32,33]. For example, factors such as personal morality and social values [4], moral values [7], cheating, performance and enforcement [34], external motivation and negative mood states [35], and sportsperson ship orientations (e.g., respect and concern for rules, officials, and social conventions) [36] have all been linked with PED use through empirical research. Yet, none of these viewpoints has proved entirely successful in providing a comprehensive understanding of doping in sport.

\section{Moral Disengagement}

Bandura's social cognitive theory of moral thought and action offers a promising approach to understanding PED use [37]. Bandura proposes engagement in transgressive activities is deterred by anticipation of negative emotions resulting from such behavior. Athletes should therefore be deterred from doping because they associate doping with unpleasant emotions such as guilt (e.g., for breaking rules), shame (e.g., in case important others find out), or fear (e.g., of unpleasant health consequences). However, Bandura also explains how people can reduce or eliminate anticipation of such emotions through use of any of eight psychosocial mechanisms collectively termed mechanisms of moral disengagement [37]. Moral disengagement allows people to conditionally endorse transgressive acts by cognitively distorting the act itself, reducing personal accountability for the act or its consequences, distorting the consequences of the act, or dehumanizing or blaming the victim of the act. Thus, moral disengagement may allow athletes to dope without experiencing associated negative emotions that should deter doping.

Evidence associating doping with moral disengagement is accumulating [38-42]. Across three studies, Lucidi et al. provided consistent support for a positive relationship between moral disengagement and intention to dope and reported doping in Italian youths [40-42]. Subsequent qualitative research by Boardley and Grix provides further support for this link, as well as specific detail on the actual moral disengagement mechanisms used, and how athletes who use PEDs apply these mechanisms. Using semi-structured interviews with nine English bodybuilders with experience of PED use, Boardley and Grix revealed the use of six mechanisms of moral disengagement [38]. These mechanisms were Displacement of Responsibility (i.e., social pressure to use PED in specific training environments), Diffusion of Responsibility (i.e., perception that PED use is acceptable because many athletes do it), Advantageous Comparison (i.e., making PED use appear inconsequential by comparing it to more harmful activities), Distortion of Consequences (i.e., avoiding or cognitively minimizing the harm caused by PED use), Moral Justification (i.e., justifying PED use on the basis of knowledge gained regarding safe use that can then be passed on to others), and Euphemistic Labeling (i.e., use of sanitizing terms such as juice or gear when referring to PED to make substances sound less harmful). Importantly, these findings have now been supported in a subsequent World Anti Doping Agency funded national investigation of moral disengagement in 64 doping bodybuilders sampled from across England [39].

Use of the mechanisms identified by Boardley and Grix is also evidenced in statements made by professional athletes known to have used PED. For example, Floyd Landis's statement that Lance Armstrong's longtime manager Johan Bruyneel introduced him to doping and that Armstrong taught him how to dope [43] are examples of displacement of responsibility. Similarly, when Tyler Hamilton explained that he felt he had to dope because almost all cyclists in the professional peloton were doping [19], he was evidencing diffusion of responsibility. Armstrong and his teammates are also reported to have referred to erythropoietin (a blood booster they used extensively) as "Edgar Allan Poe" or "butter", and the period during which doping products would produce a positive test as "glow time" [19]; these are all clear examples of euphemistic labeling. Thus, it would appear that professional athletes who use PED morally disengage. As such, the work of Boardley, Lucidi, and their colleagues, as well as anecdotal evidence from professional athletes suggests moral disengagement may play a key role in facilitating PED use.

\section{Recommendations}

Past research and theorizing has provided an understanding of the motivations for and against doping. Performance outcomes, prestige, and achievement influence PED use [6,7], and many professional athletes see doping as necessary to be competitive [5]. In addition, many athletes use PEDs for financial reasons [6]. Finally, group influences from people such as sports doctors, other competitors, and coaches can influence an athlete's decision to dope $[6,8]$. Current deterrence methods, however, appear insufficient to prevent the use of PED in sport. 
Finally, early work applying Bandura's social cognitive theory of moral thought and action suggest mechanisms of moral disengagement may play an important role in facilitating doping by allowing athletes to rationalize their PED use. Qualitative, quantitative, and anecdotal evidence suggest that engaging in moral disengagement may increase athletes' adoption and continuation of PED use. Although it is too soon to propose interventions aimed at reducing PED use based upon the tenets of Bandura's theory, it is important to be aware of the potential consequences of athletes' moral disengagement. A more detailed understanding of moral disengagement could assist in reducing PED use in the future.

\section{References}

1. Barton DA, Gold MS (2007) A review of performance enhancing drugs in professional sports and their spread to amature athletics, adolescents, and other at-risk populations. In: Performance enhancing medications and drugs of abuse (MS Gold, Ed). Binghamton, NY, Haworth Medical Press.

2. Mottram DR (2005) Prevalence of drug misuse in sport. In: Drugs in sport Hoboken NJ (ed.). Taylor \& Francis Ltd.

3. Anshel MH, Russell KG (1997) Examining athletes' attitudes toward using anabolic steroids and their knowledge of the possible effects. J Drug Educ 27: 121-145.

4. Donovan RJ, Egger G, Kapernick V, Mendoza J (2002) A conceptual framework for achieving performance enhancing drug compliance in sport. Sports Med 32: $269-284$.

5. Backhouse S, McKenna J, Robinson S, Atkin A (2007) International literature review: Attitudes, behaviors, knowledge and education - drugs in sport: past, present and future. World Anti-Doping Agency.

6. Huybers T (2010) An empirical model of athlete decisions to use performanceenhancing drugs: qualitative evidence. Qualitative Research in Sport and Exercise 2: 385-402.

7. Petroczi A, Aidman E (2008) Psychological drivers of doping: the life-cycle model of performance enhancement. Substance abuse treatment, prevention and policy $3: 7$

8. Coakley J (2007) Sports in sociology: Issues and controversies. New York McGraw-Hill.

9. Waddington I, Smith A (2009) An introduction to drugs in sport: Addicted to winning? London, Routledge.

10. Kirkwood K (2012) Defensive doping: Is there a moral justification for "If you can't beat'em - join „em?”. Journal of Sports and Social Issues 36: 223-229.

11. Homfray R (2012) Cadel Evans could be seen as the 'moral' winner of the 2005 Tour de France.

12. Shermer M (2008) The doping dilemma. Sci Am 298: 82-89.

13. Houlihan B (2002) Dying to win (2nd ed). Germany, Council of Europe Publishing.

14. Wilson DC (2006) 'Let them do drugs?' - A commentary on random efforts a shot blocking in the sports drug use game. Flordia Costal Law Review 57: 53-110.

15. Lippi G, Mattiuzzi C (2008) Pistorius ineligible for the Olympic Games: the right decision. Br J Sports Med 42: 160-161.

16. Zachary GP (2004) Steriods for everyone! Wired, 12 Retrieved September 20 2012 from

17. King MR (2012) A league of their own? Evaluating justifications for the division of sport into 'enhanced' and 'unenhanced' leagues. Sport, Ethics \& Philosophy 6: $31-45$

18. Todd J, Todd T (2009) Reflections on the 'Parallel Federation Solution' to the problem of drug use in sport. In Performance-enhancing technologies in sports: Ethical, conceptual, and scientific issues, (TH Murray, KJ Maschke and AA Wasunna, eds.). Baltimore, MD, Johns Hopkins University Press.

19. Hamilton T, Coyle D (2012) The Secret Race. London, UK, Bantam Press.
20. Sandel M (2007) The case against perfection: Ethics in the age of genetic engineering. Cambridge, MA, Harvard University Press.

21. Caplan AL (2008) Does the biomedical revolution spell the end of sport? $\mathrm{Br} J$ Sports Med 42: 996-997.

22. Johnson MB (2011) A systemic model of doping behavior. Am J Psychol 124 151-162.

23. Haidt J, Koller SH, Dias MG (1993) Affect, culture, and morality, or is it wrong to eat your dog? J Pers Soc Psychol 65: 613-628.

24. Martins R, Seefeldt V (1979) Guidelines for Children's Sports. Reston, VA AAHPERD.

25. Bilard J, Ninot G, Hauw D (2011) Motives for illicit use of doping substances among athletes calling a national antidoping phone-help service: an exploratory study. Subst Use Misuse 46: 359-367.

26. Haidt $J$ (2001) The emotional dog and its rational tail: a social intuitionist approach to moral judgment. Psychol Rev 108: 814-834.

27. Deford F (2012) Just say no: Doping diminishes all athletes. Sweetness And Light.

28. Miller B, Roberts GC, Ommundsen Y (2005) Effect of perceived motivational climate on moral functioning, team moral atmosphere perceptions, and the legitimacy of intentionally injurious acts among competitive youth football players. Psychology of Sport and Exercise 6: 461-477.

29. Sage L, Kavussanu M (2007) Multiple goal orientations as predictors of mora behavior in youth soccer. The Sport Psychologist 21: 417-437.

30. Bredemeier BJ, Shields DL (1986) Moral growth among athletes and nonathletes: a comparative analysis. J Genet Psychol 147: 7-18.

31. Ebbeck V, Gibbons SL (2003) Explaining the self-conception of perceived conduct using indicators of moral functioning in physical education. Res $Q$ Exerc Sport 74: 284-291.

32. Miller BW, Roberts GC, Ommundsen Y (2004) Effect of motivational climate on sportspersonship among competitive youth male and female football players Scand J Med Sci Sports 14: 193-202.

33. Vallerand RJ, Briere NM, Blanchard CM, Provencher PJ (1997) Developmen and validation of the multidimensional sportspersonship orientation scale. Journal of Sport and Exercise Psychology 19: 197-206.

34. Gucciardi DF, Jalleh G, Donovan RJ (2011) An examination of the Sport Drug Control Model with elite Australian athletes. J Sci Med Sport 14: 469-476.

35. Vâjiala G, Epuran M, Stanescu M, Potzaichin I, Berbecaru C (2010) Relation between motivation and temptation for using the doping substances in high performance sports. Science, Movement, \& Health 10: 207-212.

36. Miquelon P, Valois P, Goulet C, Buist A, Vallerand RJ (2006) A motivationa model of performance-enhancing substance use in elite athletes. Journal of Sport and Exercise Psychology 28: 511-520.

37. Bandura A (1991) Social cognitive theory of moral thought and action. In: WM Kurtines and JL Gewirtz, eds. Handbook of moral behavior and development theory research and applications. Hillsdale, NJ, Lawrence Erlbaum Associates.

38. Boardley ID, Grix J (in press) Doping in bodybuilders: A qualitative investigation of facilitative psychosocial processes. Qualitative Research in Sport, Exercise, and Health.

39. Boardley ID, Grix J, Dewar A (in preparation) A National Investigation of Psychosocial Factors Facilitating Doping in English Bodybuilders. Journal of Sport \& Exercise Psychology.

40. Lucidi F, Grano C, Leone L, Lombardo C, Pesce C (2004) Determinants of the intention to use doping substances: An empirical contribution in a sample of Italian adolescents. International Journal of Sport Psychology 35: 133-148.

41. Lucidi F, Zelli A, Mallia L, Grano C, Russo PM, et al. (2008) The social-cognitive mechanisms regulating adolescents' use of doping substances. J Sports Sci 26: $447-456$

42. Zelli A, Mallia L, Lucidi F (2010) The contribution of interpersonal appraisals to a social-cognitive analysis of adolescents' doping use. Psychology of Sport and Exercise 11: 304-311.

43. Whitecomb D (2012) Armstrong teammate Floyd Landis admits defrauding supporters. Reuters. 